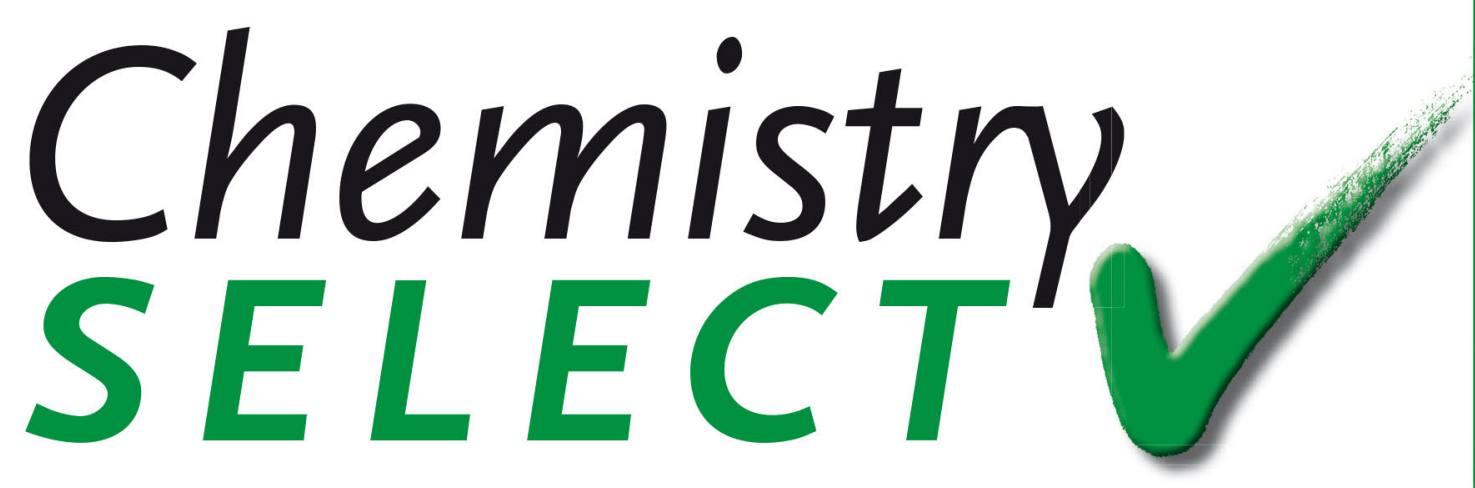

A journal of

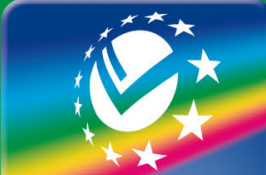

ChemPubSoc Europe

www.chemistryselect.org

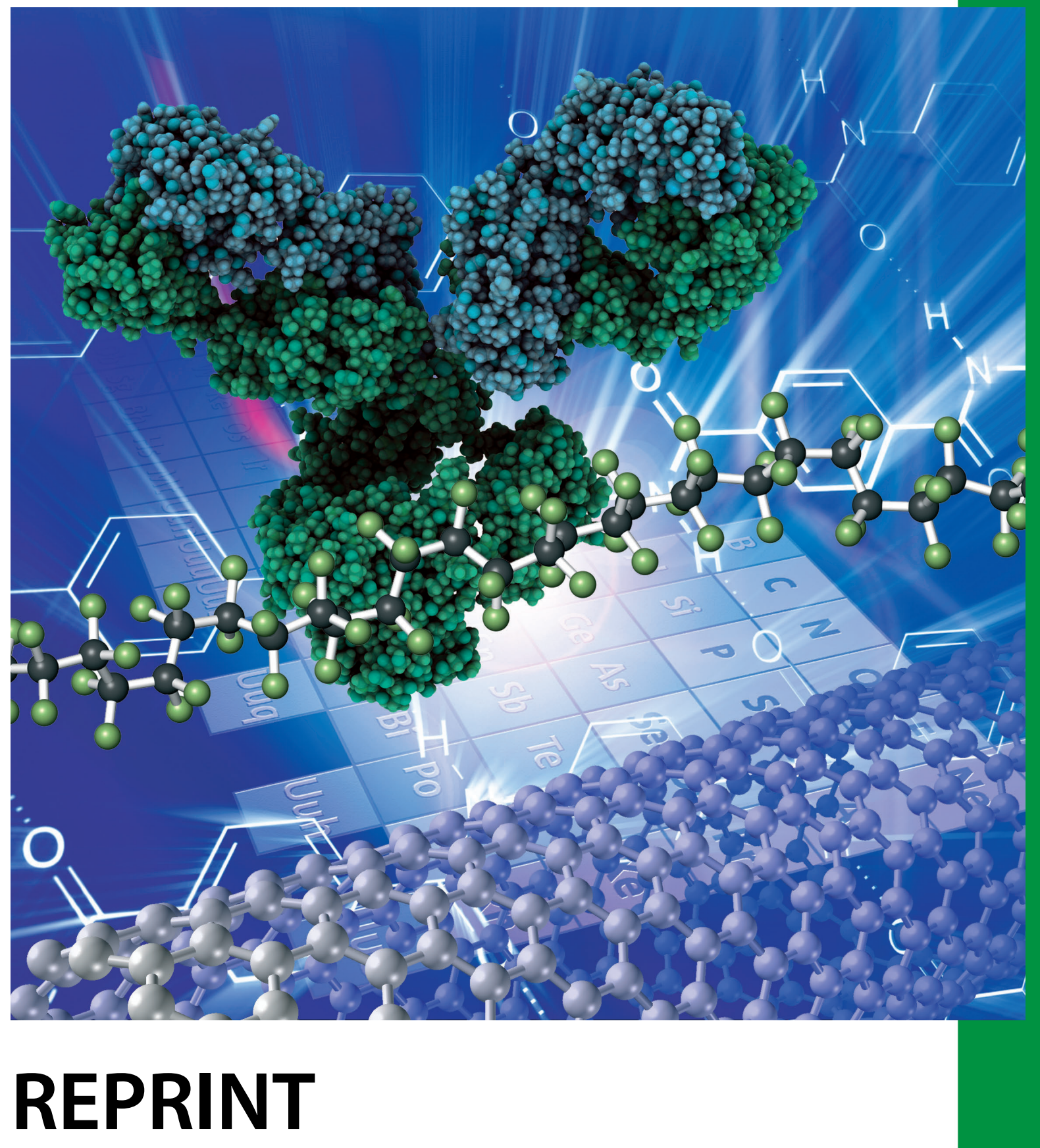

WILEY-VCH 


\title{
Scavenging of Hydrogen Peroxide by Allyl Methyl Sulfide and Diallyl Sulfide, Two Garlic Active Compounds: A Theoretical Study
}

\author{
Mario G. Díaz, ${ }^{[a]}$ Esteban G. Vega-Hissi, ${ }^{[a]}$ Matias F. Andrada, ${ }^{[b]}$ and Juan C. Garro Martinez ${ }^{*[a]}$
}

We study potential scavenging of hydrogen peroxide by Allyl Methyl Sulfide and Diallyl Sulfide, two garlic components. The antioxidant properties of garlic are attributed to organosulfide compounds, which react with reactive oxygen species preventing the oxidative stress. We used the B3LYP functional for structure analysis and M06-2X functional for the reactions employing gaseous, aqueous and non-polar environments. The conformational analysis and Fukui functions allowed the selection of the initial structures and the region of nucleophilic attack by hydrogen peroxide. The scavenging reactions analyzed are: 1) Sulfoxidation; 2) Epoxidation; and 3) Hydro-

\section{Introduction}

The organosulfide compounds are organic species that contain one or more sulfur atoms in its structure. Garlic (Allium sativum) has a large number of organosulfide compounds that show different properties. ${ }^{[1-4]}$ Some of the main compounds present in garlic are shown in Figure 1.There is much information about the structure, bioactivity and health benefits of these interesting compounds. There is evidence of the antiviral, antibacterial, antiparasitic activity and that it helps to decrease cholesterol levels and inhibit platelet aggregation and tumor growth. ${ }^{[1-6]}$ Due to the wide functionality of garlic, it has gained interest by food industry engineering who have used it as a natural source of antimicrobial and antioxidant compounds to increase the shelf life of food (food preservation), mainly, in order to delay lipid oxidation in meat products, and as dietary supplements preventing the oxidative stress. ${ }^{[7,8]}$ Current investigations are particularly centered on the inhibition of the formation or reduction of the reactive oxygen species (ROS), specifically, hydrogen peroxide that is eliminated enzymatically by glutathione peroxidase..$^{[9-14]}$

[a] M. G. Díaz, Dr. E. G. Vega-Hissi, Dr. J. C. Garro Martinez IMIBIO, CONICET, Facultad de Química, Bioquímica y Farmacia, Universidad Nacional de San Luis Avenida Ejército de los Andes 950, 5700 San Luis, Argentina

E-mail: jcgarro@unsl.edu.ar

[b] Dr. M. F. Andrada

Facultad de Química, Bioquímica y Farmacia, UniversidadFacultad de Química, Bioquímica y Farmacia, Universidad Nacional de San Luis, Chacabuco 915, 5700 San Luis, Argentina

E-mail: mfandrada77@gmail.com

Supporting information for this article is available on the WWW under https://doi.org/10.1002/slct.201904725 genation. Through the intrinsic reaction coordinate, the energy profile, the activation energies, the rate constant and its temperature-dependence were calculated. The results predict that reactions occur slowly and hydrogenation is not a feasible process. Finally, the sulfoxidation of Allyl Methyl Sulfide and Diallyl Sulfide resulted to be more thermodynamically and kinetically favorable than epoxidation (rate constant values, $10^{-10} \mathrm{~s}^{-1}$, in comparison with $10^{-18} \mathrm{~s}^{-1}$ from epoxidation), becoming the most probable pathway for hydrogen peroxide scavenging.

Despite the advantage of garlic usage in the food preservation and dietary supplements industry, relative little is known about the kinetic and mechanism of the ROS scavenging processes by organosulfide garlic compounds.

Previously, we carried out computational studies of the thermodynamic and kinetics aspect of allyl methyl disulfide (AMD) with hydrogen peroxide and hydroxyl radical. ${ }^{[15-17]}$ In addition, several authors have published theoretical and experimental studies of the reaction of the antioxidants compounds focused in the elimination of ROS species, which highlight the actual interest on this issue. ${ }^{[18-23]}$ Here, we research the scavenging mechanism of hydrogen peroxide by two garlic active compounds: Allyl Methyl Sulfide (AMS) and Diallyl Sulfide (DAS). These interesting garlic components show a special interest as important antioxidant agents. ${ }^{[5-8]}$ In addition, to the best of our knowledge, the majority of the recent theoretical studies that analyze the scavenging reactions of ROS have been performed within gaseous environments and few others simulating an aqueous phase. However, it is known that the organosulfide garlic compounds have poor or even null aqueous solubility. Instead, they show high lipid solubility. Only two compounds illustrated in Figure 1 are water-soluble: the S-allylcysteine and S-allylmercaptocysteine. ${ }^{[2]}$ Thus, taking into account that AMS and DAS, as many other antioxidants, are soluble in lipid solvents (non-polar environments), we have also chosen to analyze the scavenging mechanism in a medium whose dielectric constant value is close to that of the inner part of a lipid membrane such as cyclohexane. ${ }^{[25-27]}$

Therefore, in the current work we carried out a theoretical quantum study of the thermochemical and kinetic aspects of the different possible scavenging mechanisms of hydrogen peroxide by AMS and DAS in gaseous, aqueous and lipid 
<smiles>C=CCSC</smiles>

Allyl-sulfide<smiles>C=CCSCC=C</smiles>

Diallyl-sulfide<smiles>C=CCSSCC=C</smiles>

Diallyl-disulfide<smiles>C=CCSSSCC=C</smiles>

Diallyl-trisulfide<smiles>C=CCSS(=O)CC=C</smiles>

Allicin<smiles>C=CCCSCCC=C</smiles>

Diallyl-methyl-sulfide<smiles>C=CCSSCC(N)C(=O)O</smiles>

S-allylmercapto-cysteine<smiles>CC=[SH](=O)C=S</smiles>

Thiacremonone<smiles>C=CCS(=O)CC(N)C(=O)O</smiles><smiles>C=CCSCC(N)C(=O)O</smiles><smiles>C=CCSSC=CCS(=O)CC=C</smiles>

Ajoene

Figure 1. Main organosulfide compounds of garlic.

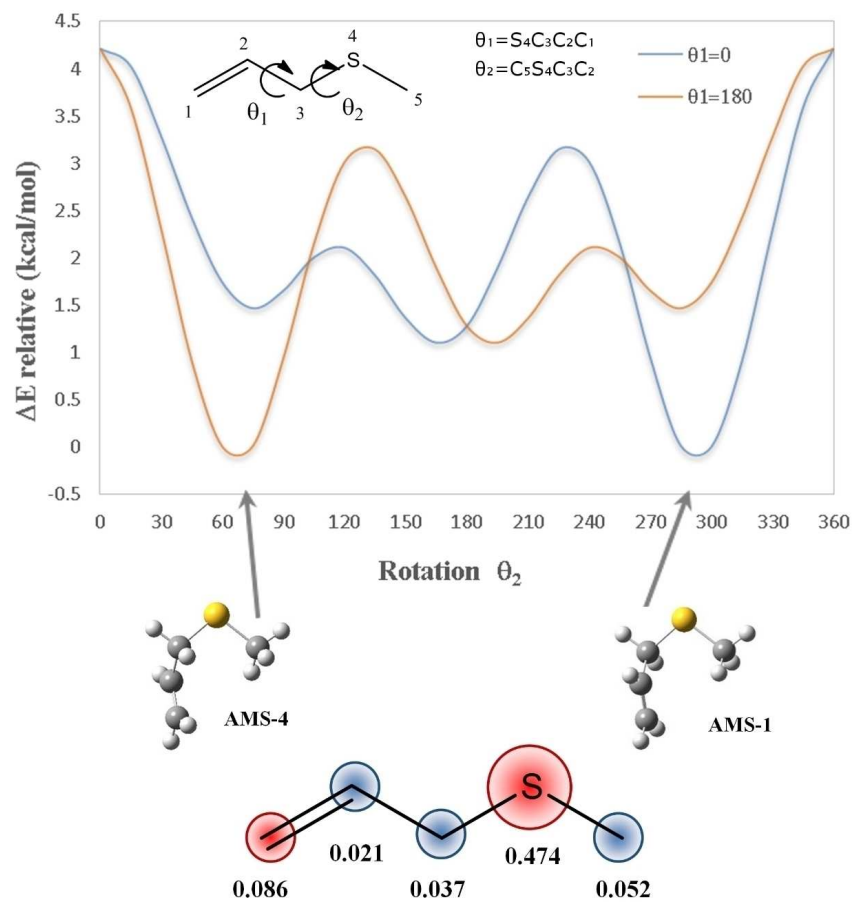

Figure 2. Topological structure, internal dihedrals, minimum energy conformations and Fukui function values of AMS. In red possible region of nucleophilic attack.

environment. Thus, we contribute valuable information for the knowledge of the kinetic and reaction mechanism of the organosulfide active compounds present in garlic that could be involved in food preservation and prevent the oxidative stress.

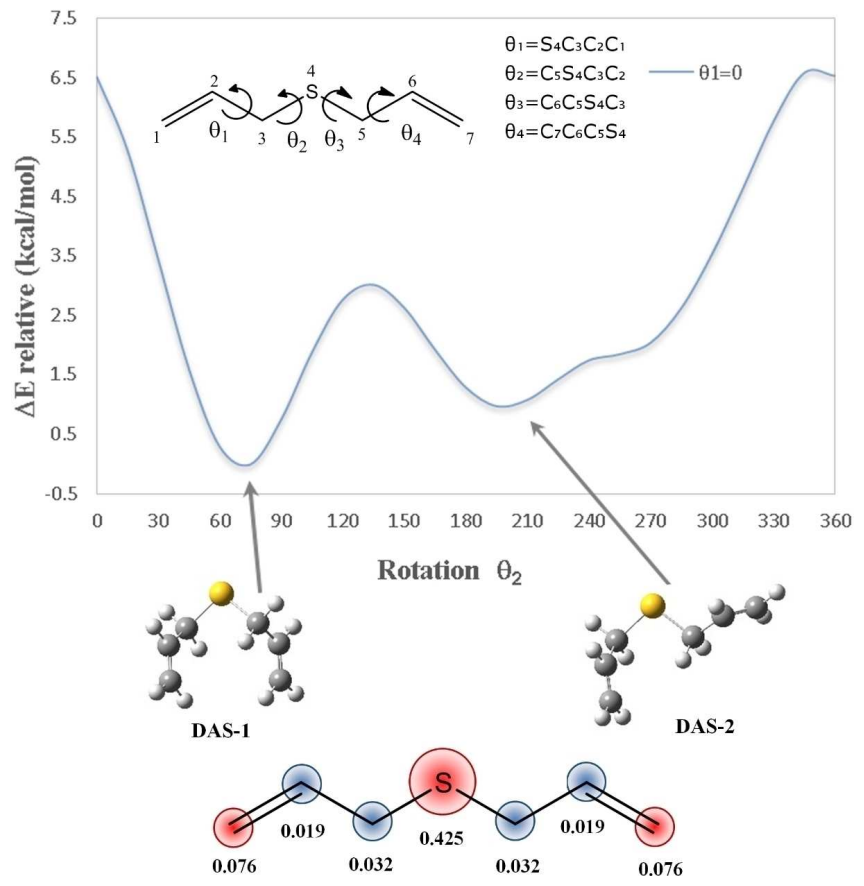

Figure 3. Topological structure, internal dihedrals, minimum energy conformations and Fukui function values of DAS. In red possible region of nucleophilic attack.

\section{Computational methods}

All the quantum calculations were performed using the Gaussian 09 program. ${ }^{[28]}$ The initial conformational analysis of AMS and DAS was carried out with the B3LYP density 


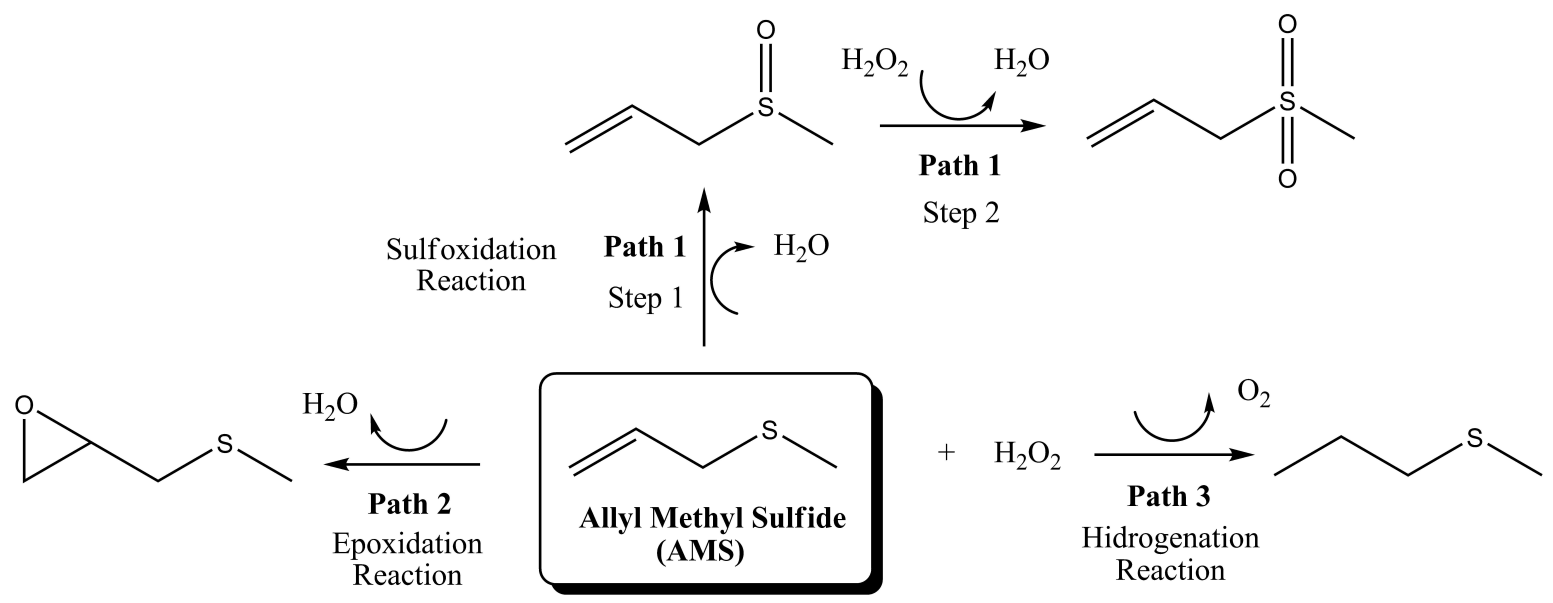

Figure 4. Proposed pathways for AMS and hydrogen peroxide reaction.<smiles>C1OC1CSCC1CO1</smiles><smiles>C=CCSCC1CO1</smiles><smiles>C=CCSCC1CO1</smiles><smiles>C=CCS(=O)CC=C</smiles>
$\begin{array}{cr}\text { Sulfoxidation } & \text { Path } 4 \\ \text { Reaction } & \text { Step 1 }\end{array} \uparrow \mathrm{C}^{\mathrm{H}_{2} \mathrm{O}}$

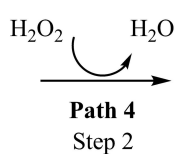
Step 2<smiles>C=CCS(=O)(=O)CC=C</smiles>
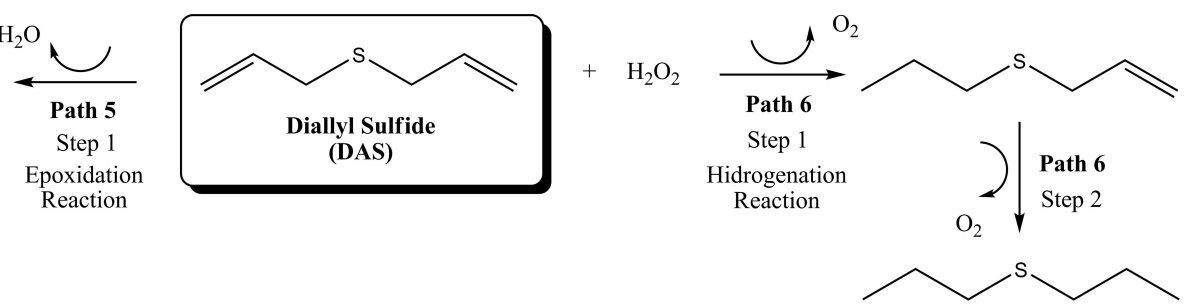

Figure 5. Proposed pathways for DAS and hydrogen peroxide reaction.

functional theory method and $6-31++\mathrm{G}(3 \mathrm{df}, 2 \mathrm{p})$ basis set. $^{[29,30]}$ All conformer geometries were fully optimized and frequencies were calculated. In addition, we calculated the Fukui functions to elucidate the favorable sites for chemical attack. ${ }^{[31-33]}$ With this information, we presented a series of sulfoxidation, epoxidation and hydrogenation reactions between AMS (or DAS) with hydrogen peroxide.

A first study on the spontaneity of the proposed reactions was performed using the thermodynamic cycle descripted by other authors in several papers. ${ }^{[34-36]}$ Here, we calculated the reaction Gibbs free energy change $\left(\Delta G_{R}\right)$ from the Gibbs free energy of the individual reactants and products, such as is indicated in the bibliography, but also we used the Gibbs free energy of the reactants and products complexes.

These proposed reactants complexes (AMS $\cdots \mathrm{H}_{2} \mathrm{O}_{2}$ and DAS $\cdots \mathrm{H}_{2} \mathrm{O}_{2}$ ) and products complexes were optimized and characterized by frequency calculations with the Minnesota functional M06-2X and the $6-31++G(3 d f, 2 p)$ basis set. ${ }^{[37]}$ The transition states structures were obtained using the transition state Berny optimization method (TS Berny) and the synchro- nous quadratic transit methods (QST2). ${ }^{[38]}$ The connectivity between the transition state (TS) reaction reactants or products was validated by means of intrinsic reaction coordinate (IRC) calculations using the same level of theory. ${ }^{[39]}$

The scavenger reactions were studied in the gas phase, and solvent effect was taken into account by the density-based solvation model (SMD). ${ }^{[0]}$ To model a non-polar environment, cyclohexane solvent was chosen because it presents a dielectric constant close to a lipid membrane. ${ }^{[25-27]}$

Finally, the rate constants and the temperature-dependence were calculated by the transition-state theory (TST) employing the KiSThelP program. ${ }^{[41]}$

\section{Results and discussion}

\section{Conformational analysis and Fukui functions}

A conformational analysis of AMS and DAS was performed with the aim to find the most stable conformations to be used as 

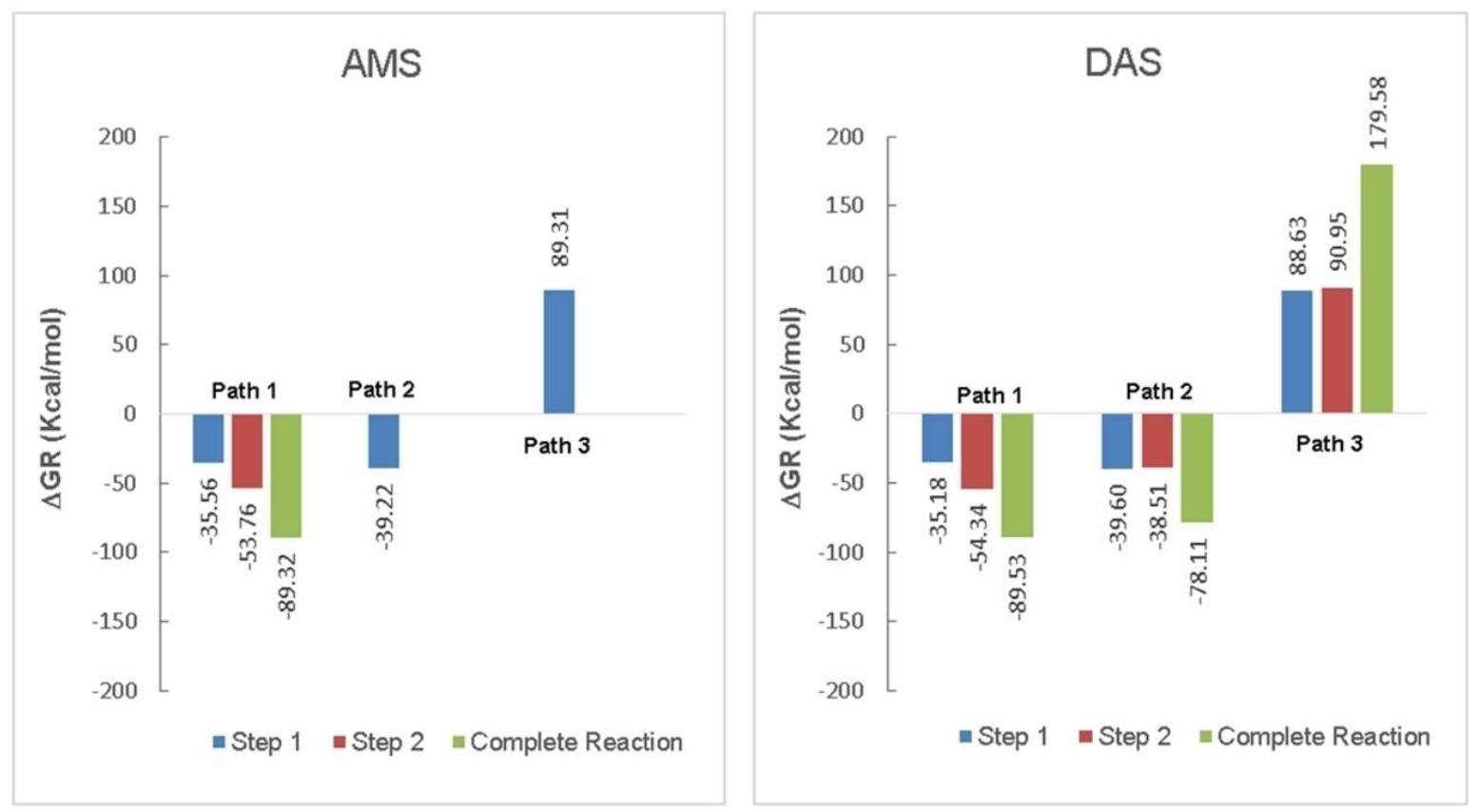

Figure 6. Gibbs Free Energy variation $\left(\Delta G_{R}\right)$ express in $\mathrm{kcal} / \mathrm{mol}$. Thermodynamic cycle results.

initial molecular structure in the subsequent thermodynamic and kinetic study.

Then, we estimated the Fukui functions of the most stable conformations of AMS and DAS, which identified the sensitive region for possible nucleophilic attack.

\section{Allyl Methyl Sulfide (AMS)}

The molecular structure of AMS allows the free rotation of the two dihedral angles defined in Figure 2 . We carried out a full $\left(360^{\circ}\right)$ rotation of dihedral $\theta_{2}$ with a step of $15^{\circ}$ and initial values for $\theta_{1}$ of $0^{\circ}$ and $180^{\circ}$. Thus, we generated two curves of potential energy (PEC) that have a significant similitude elucidating the high molecular symmetry of AMS, Figure 2 . The line plots show three regions of low energy corresponding to three stable conformations of dihedral $\theta_{2}$. Table $1 \mathrm{~S}$ lists the values of the dihedrals angles, the relative energies expressed in $\mathrm{kcal} / \mathrm{mol}$ and absence of imaginary frequencies for each stable conformer. We found that the molecular structure do not present significant changes in either of the phases (gaseous, aqueous or non-polar) studied. In addition, the results indicate that $\theta_{1}$ take final values next to $115^{\circ}$ and $-115^{\circ}$. This change from the initial value of $0^{\circ}$ and $180^{\circ}$ is due to the relaxed mode used in the PEC generation. The final values of $\theta_{2}$ and the similar electronic energies found for equivalent conformers (AMS- 1 and AMS-4, AMS-2 and AMS-5, AMS-3 and AMS-6) suggest a significant molecular symmetry.

According to the results, we selected the AMS-4 conformation as the most stable structure of AMS that show a high molecular symmetry with the AMS-1 conformation. The most stable three-dimension structure of AMS is shown in Figure 2, along with the topological representation of AMS structure with the identified regions of high Fukui function values. The Fukui function values indicate that the main target region for the nucleophilic attack is the sulfur atom (0.474) and a secondary site appears at the terminal vinyl carbon (0.086).

\section{Diallyl Sulfide (DAS)}

Hoyos et al. performed an experimental and theoretical study of DAS. ${ }^{[42]}$ Here, we implemented a more simple conformational analysis obtaining the minimum energy conformation in agreement with the experimental structure characterized by Hoyos.

We defined four dihedral angles into the structure of DAS, see Figure 3. The values of dihedrals $\theta_{1}$ and $\theta_{2}$ were taken from the optimized structure of AMS, reducing the study to only two

\begin{tabular}{|c|c|c|c|c|c|c|c|}
\hline & & $\begin{array}{l}\Delta G_{R} \\
\text { Gaseous }\end{array}$ & Aqueous & Non-polar & $\begin{array}{l}\log k \\
\text { Gaseous }\end{array}$ & Aqueous & Non-polar \\
\hline \multirow{2}{*}{ Sulfoxidation } & Step 1 & -50.35 & -54.38 & -50.92 & -18.38 & -10.25 & -16.30 \\
\hline & Step 2 & -72.49 & -75.50 & -75.22 & -20.71 & -13.42 & -17.51 \\
\hline Epoxidation & & -55.67 & -57.00 & -57.28 & -25.57 & -18.20 & -23.23 \\
\hline Hydrogenation & & 41.68 & 47.25 & 42.07 & -30.84 & -31.95 & -31.20 \\
\hline
\end{tabular}



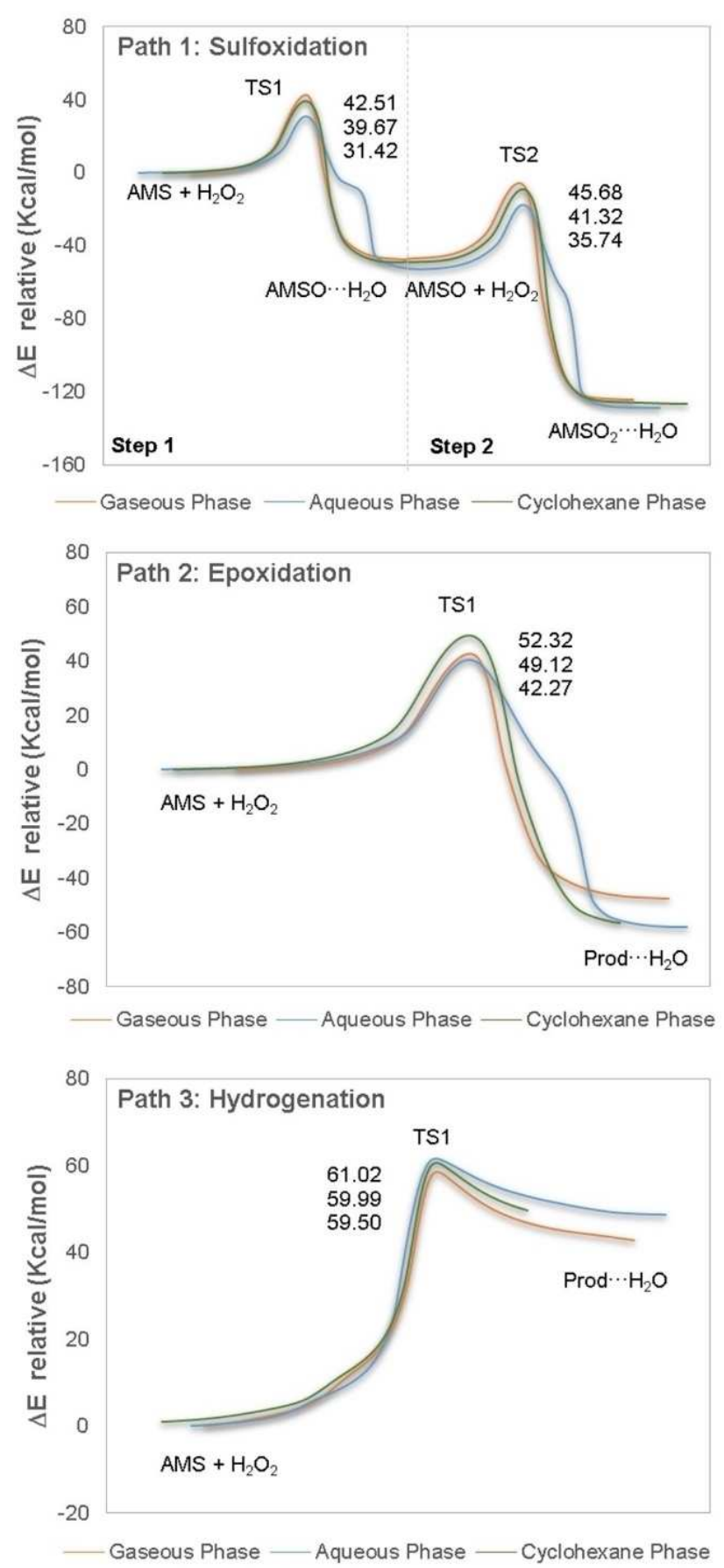

Figure 7. IRC of the sulfoxidation, epoxidation and hydrogenation for the reaction of AMS with hydrogen peroxide.

angles, $\theta_{3}$ and $\theta_{4}$. Additionally, the molecular symmetry of DAS let us assume that the dihedral $\theta_{4}$ will show values next to $115^{\circ}$ or $-115^{\circ}$, such as $\theta_{1}$ in AMS. According to the selected conformation of AMS, we kept the value of $-115^{\circ}$ for $\theta_{4}$ and carried out a free rotation of the dihedral $\theta_{3}$ (Figure 3). As can be seen in this figure, there are two minimum energy wells that correspond to stables conformers.

The results of the optimization of the stable conformers in gaseous, aqueous and non-polar phases are listed in Table 2S.
In spite of the fact that all the calculations were carried out in relax mode, we noted that the dihedral values do not change in comparison of the equivalent dihedral angles of AMS. The selected stable molecular structure (conformer DAS-1) and the Fukui function values are illustrated in Figure 3. From Fukui function values, we identified that the sulfur atom (0.425) and both terminal vinyl carbon atoms (both with a value of 0.076 ) are the possible targets for nucleophilic attack.

\section{Reaction pathway and thermodynamic analysis}

Through the conformational analysis, the initial structures of AMS and DAS were selected and the Fukui function calculation highlighted the target region where these organosulfide compounds can receive a nucleophilic attack by hydrogen peroxide. The information collected from other authors indicates that the sulfide compound can experience a simple or a double sulfoxidation reaction by hydrogen peroxide. ${ }^{[18-23,43,44]}$ Besides, the presence of the vinyl moiety results in the possibility of epoxidation or hydrogenation reactions. ${ }^{[45-47]}$ Therefore, we proposed for the AMS and DAS the following reactions:

- Attack on the sulfur atom through an oxidation reaction, path 1 (AMS) and path 4 (DAS), Figures 4 and 5.

- Attack on the vinyl carbon atoms: an epoxidation reaction, path 2 (AMS) and path 5 (DAS) and a hydrogenation reaction path 3 (AMS) and path 6 (DAS), Figures 4 and 5.

In some reactions, the products can react further with hydrogen peroxide if it is in excess, as is explained above for the sulfoxidation reactions. Thus, we analyzed a second step in each pathway when it is possible. Several combinations of possible reactions can arise in each pathway: an oxidation (step 1) can be followed by an epoxidation or hydrogenation reaction (step 2) or other combinations. However, in this paper we consider only pathways with the same reaction type. Consequently, the only 2-step pathway studied for AMS is the sulfoxidation, Figure 4. Whereas, all reaction types (sulfoxidation, epoxidation and hydrogenation) involving DAS were studied in two steps, Figure 5.

A thermodynamic analysis was performed to ascertain the spontaneity or feasibility of each proposed reaction. Figure 6 depicts the $\Delta G_{R}$ (aqueous) values calculated using the thermodynamic cycle. We found that step 1 of hydrogenation reaction of AMS and DAS (paths 3 and 6, respectively) are not spontaneous processes. The second hydrogenation step of DAS presents a similar Gibbs free energy value of step 1 leading to a non-spontaneous overall process.

By contrast, we found that the sulfoxidation and epoxidation reactions (paths 1, 2, 4 and 5) are spontaneous processes which indicate that the formation of the products is favorable. According to step $1 \Delta G_{R}$ values, epoxidation is preferred over sulfoxidation. However, the fact that sulfoxidation proceeds further (through step 2) the overall reaction results thermodynamically preferred with the most negative $\Delta G_{R}$ values, even more negative than the 2-step epoxidation of DAS (Figure 6).

Despite of the negative $\Delta G_{R}$ values, which mark the major thermodynamic feasibility of the sulfoxidation, in contrast with 


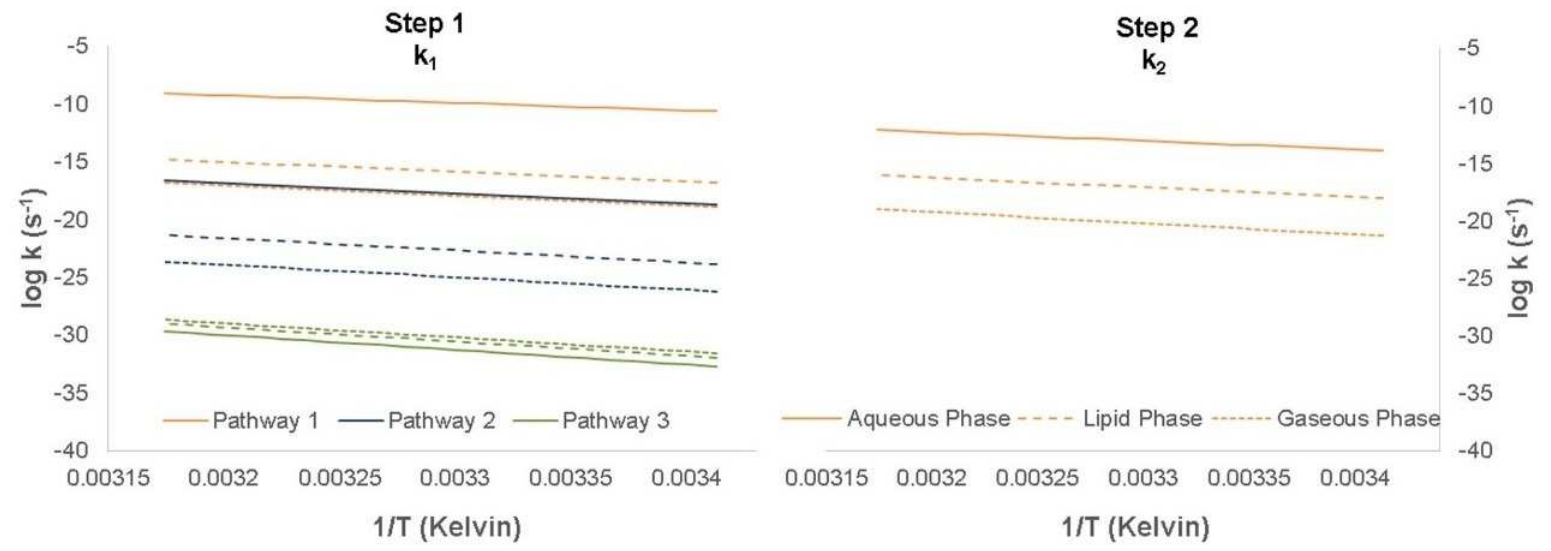

Figure 8. Variation of the rate constants with the temperature (293-313 K) for the AMS reactions. Solid line: Aqueous Phase. Dotted line: Gaseous Phase. Dashed line: Lipid Phase.

\begin{tabular}{|c|c|c|c|c|c|c|c|}
\hline & & $\begin{array}{l}\Delta \mathrm{G}_{\mathrm{R}} \\
\text { Gaseous }\end{array}$ & Aqueous & Non-polar & $\begin{array}{l}\log \mathbf{k} \\
\text { Gaseous }\end{array}$ & Aqueous & Non-polar \\
\hline \multirow{2}{*}{ Sulfoxidation } & Step 1 & -49.09 & -51.46 & -49.92 & -20.57 & -12.04 & -18.54 \\
\hline & Step 2 & -74.27 & -74.49 & -75.48 & -18.98 & -13.07 & -17.09 \\
\hline \multirow{2}{*}{ Epoxidation } & Step 1 & -55.75 & -57.29 & -55.20 & -25.64 & -17.46 & -24.52 \\
\hline & Step 2 & -54.81 & -57.60 & -55.36 & -25.84 & -17.69 & -24.59 \\
\hline \multirow{2}{*}{ Hydrogenation } & Step 1 & 40.98 & 46.99 & 43.01 & -30.61 & -31.74 & -30.71 \\
\hline & Step 2 & 41.38 & 48.64 & 41.22 & -31.16 & -31.59 & -31.32 \\
\hline
\end{tabular}

the others paths, this data do not provide information about the kinetics of the reaction and is only an indicative of the spontaneity of the processes.

\section{Intrinsic reaction coordinates and kinetic analysis}

We carried out a tracing of all pathways in different environments: gaseous, aqueous and non-polar. The structures of the reactants complexes (AMS $\cdots \mathrm{H}_{2} \mathrm{O}_{2}$ and DAS $\cdots \mathrm{H}_{2} \mathrm{O}_{2}$ ) were built from the most stable conformation of AMS and DAS, and optimized and characterized by frequency calculations. Then, we proposed probable products complexes to obtain the TS structures using the advantages of the TS Berny and QST2 approaches. In the reactions with two steps, the products of the first step were optimized as the new reactants of the second step adding a molecule of hydrogen peroxide. In these cases, we proposed new final products and a new TSs for the second steps.

The minimum energy reaction pathway between the TSs and its reactants and products complexes of AMS and DAS are shown in Figure 7 and Figure 9, respectively. The pathways with a consecutive step are identified with step 1 and step 2 and the correspondent TSs as TS1 and TS2. In addition, the plot presents the activation energy (expressed in $\mathrm{kcal} / \mathrm{mol}$ ) for each step calculated from reactants and intermediaries complexes.

Table 1 and 2 list the $\Delta G_{R}$ values of AMS and DAS calculated using the optimized reactants and products complexes. These values follow the same trend as the values calculated considering isolated molecules in Figure 6: hydrogenation is clearly a non-spontaneous process and both sulfoxidation and epoxidation are thermodynamically spontaneous reactions. This tendency is independent of the environments studied.

The activation energies show significant differences when different environments (gas, aqueous, non-polar) are taken into account. Values are reported in Figure 7. The lowest energy barriers of sulfoxidation and epoxidation reactions are obtained with aqueous phase, whereas the lowest barrier of hydrogenation is achieved in gaseous phase. The overall results indicate that sulfoxidation has the lowest activation energy and is kinetically favored over the other reaction types studied in here. The molecular structure of the reactants and products complexes and the TSs of AMS reaction in non-polar medium are shown in Figure $1 S$ of the supplementary material. To summarize the figure, only the optimized structures in nonpolar medium are presented.

Then, we calculated the correlation of the rate constant $(k)$ with temperature along a temperature range from $293 \mathrm{~K}$ to $313 \mathrm{~K}$ and a pressure of $1 \mathrm{~atm}$. Figure 8 illustrates the Arrhenius plot (log $k$ versus $1 / T(k)$ ) for each step of each AMS reaction. Here, it is clear that three paths present similar linear behavior with temperature variation and the sulfoxidation (orange line) is the dominant process due to its highest rate constant value. The logarithm of the rate constants are tabulated in Table 1. The values indicate that all proposed reactions will occur very slowly. The AMS sulfoxidation is the reaction that shows the 

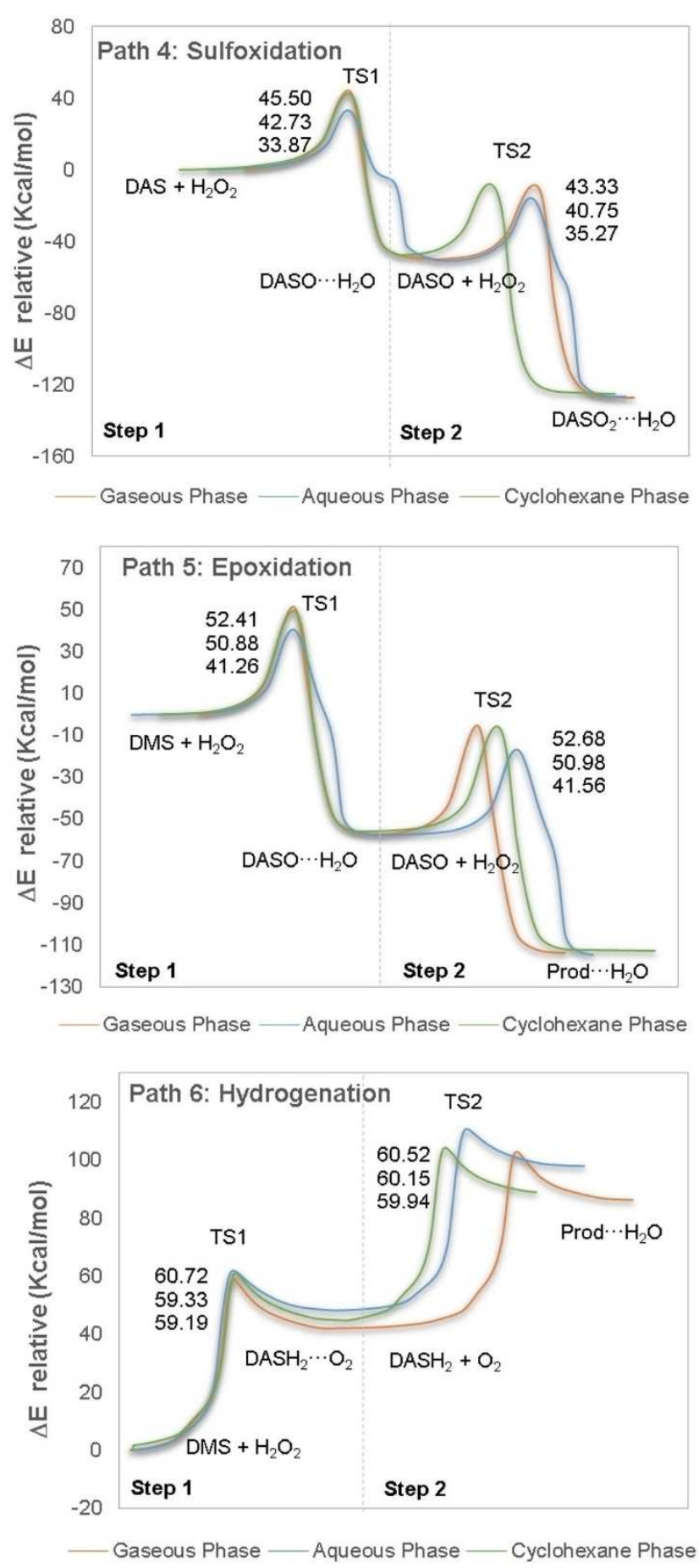

Figure 9. IRC of the sulfoxidation, epoxidation and hydrogenation for the reaction of AMS with hydrogen peroxide.

highest rate constant with values according to those found by another authors for organosulfide compounds $\left(10^{-11} \mathrm{~s}^{-1}\right){ }^{[48]}$ This is consistent with the Fukui function value over the sulfur atom which indicates that this is the main target region for the hydrogen peroxide nucleophilic attack.

The reactions involving DAS present a similar behavior to reactions of AMS. The sulfoxidation and epoxidation are spontaneous processes while hydrogenation is a non-spontaneous reaction, according to the $\Delta G_{R}$ values calculated from the reactant and products complexes. Unlike AMS, the epoxidation and hydrogenation reactions that DAS can go through have two steps with subtle differences of the $\Delta G_{R}$ values between them. The molecular structure of reactants, products and TSs found in non-polar phase are illustrated in Figure $2 \mathrm{~S}$ of supplementary material.

The lowest activation energy values were found for the sulfoxidation in aqueous phase $(33.87 \mathrm{kcal} / \mathrm{mol}$ for step 1 and $35.27 \mathrm{kcal} / \mathrm{mol}$ for step 2). The consecutive steps of the epoxidation and hydrogenation processes showed very similar activation energy values $(41 \mathrm{kcal} / \mathrm{mol}$ and $59 \mathrm{kcal} / \mathrm{mol}$, respectively), see Figure 9. The temperature dependence of $k$ (explored in the range 293-313 K) is depicted in the Arrhenius plot of Figure 10 and log $\mathrm{k}$ values collected in Table 2. We found a linear dependence and similar behavior with temperature in the three paths of DAS, as shown in Figure 10. It can be seen from this figure that the reaction proceed more rapidly in aqueous phase (orange and blue completed lines).

Thus, as was found for DAS, the activation energies and the rate constants indicate that the sulfoxidation is the reaction kinetically favorable compared to the rest of the reactions analyzed.

As can be seen in the IRC plots (Figures 7 and 9), the sulfoxidation reactions of AMS and DAS present a similar energy profile. In fact, the activation energy of each step is similar between the compounds. The same situation occurs with step 1 of the epoxidation (paths 2 and 5) and hydrogenation (paths 3 and 6 ) reactions, see Figures 7 and 9. This suggests that each step of the reactions analyzed is independent between them and do not reflect if the compounds have one or two allyl groups or if exists a previous oxidation in the sulfide atom, a previous epoxidation or hydrogenation of DAS.

Besides, we noted that although AMS and DAS are soluble in lipids, the use of an environment that simulate a lipid membrane environment (cyclohexane), does not lead to significant changes in reaction energy profiles as might be expected. In fact, only the hydrogenation reaction, which produces a less polar compound, presents in non-polar phase an insignificant lower activation energy value than in aqueous phase. However, the fact that sulfoxidation and epoxidation reactions increase the polarity of AMS and DAS, leads to a better stabilization of TSs in aqueous phase and lower activation energy values when water is considered as solvent.

Structural alignment of the optimized TSs molecular structures of AMS and DAS is shown in Figures 11 and 12, respectively. As can be seen, all structures are similar and present RMSD (root mean square deviation) values lower than $0.5 \AA$ using the gas phase structure as template. We only found a small variation in the orientation of hydrogen peroxide in TS1 and TS2 of sulfoxidation of DAS in aqueous phase.

Thus, the TSs show a similar three-dimentional conformation and the small structural variation (without involving any stabilizing interaction) do not constitute an important change that justify the activation energy values. We think that the high constant dielectric values of water $(\varepsilon=78.5)$ in relation to 

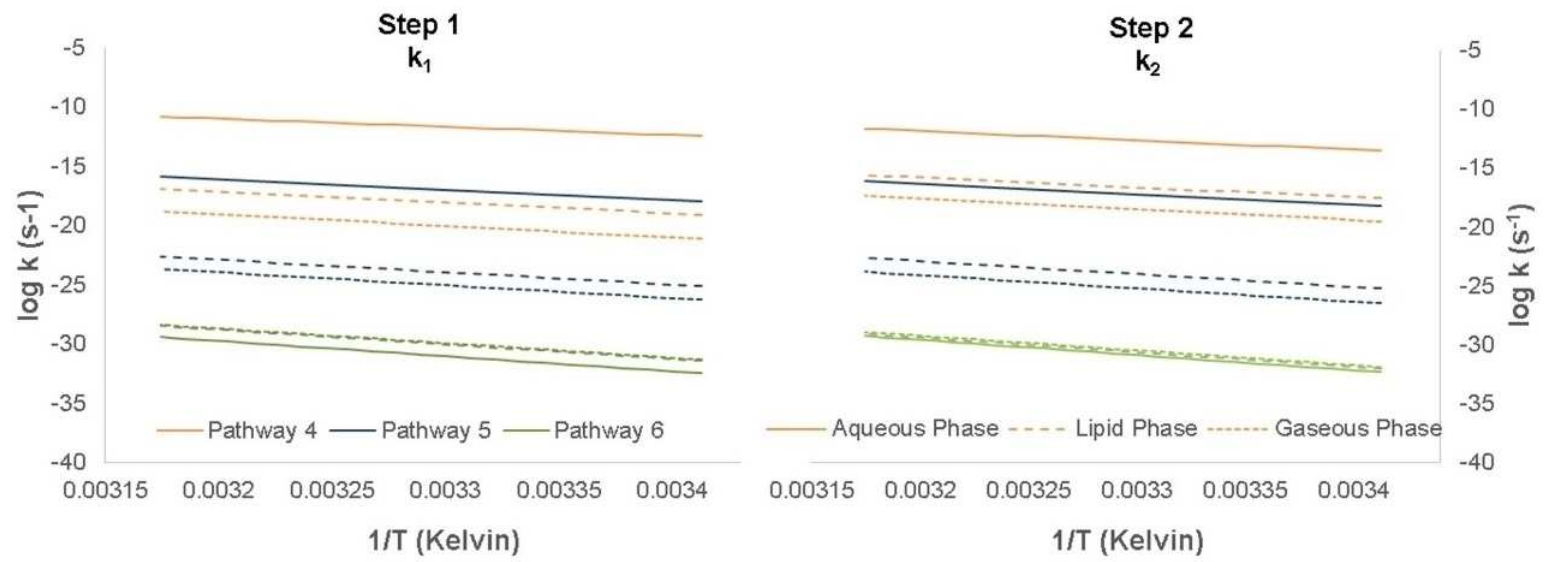

Figure 10. Variation of the rate constants with the temperature (293-313 K) for the DAS reactions. Solid line: Aqueous Phase. Dotted line: Gaseous Phase. Dashed line: Lipid Phase.
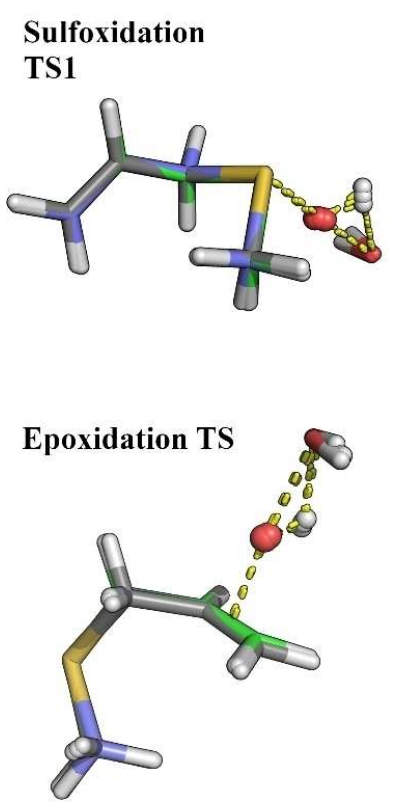

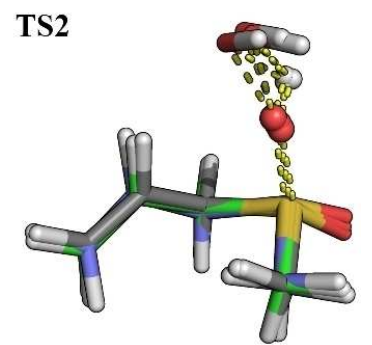

Hydrogenation TS

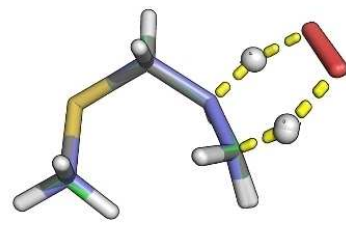

Figure 11. Overlap of the transition states (TS) of the AMS reactions in different environments. Molecules are represented in sticks and carbon atoms are colored according to the phase: gray, gaseous phase; blue, aqueous phase; and green, cyclohexane phase.

vacuum $(\varepsilon=1.0)$ and cyclohexane $(\varepsilon=2.02)$ phases, and also the polarization of water, are responsible for the aqueous phase TSs lower energies.

\section{Conclusions}

In this work, the thermodynamic and kinetic features of three different scavenger reactions of hydrogen peroxide by AMS and DAS were theoretically analyzed using the B3LYP functional for the structural study and M06-2X functional for the kinetic analysis. The proposed pathways, based on the nucleophilic target region revealed by Fukui function, were Sulfoxidation (pathway 1 and pathway 4), epoxidation (path-
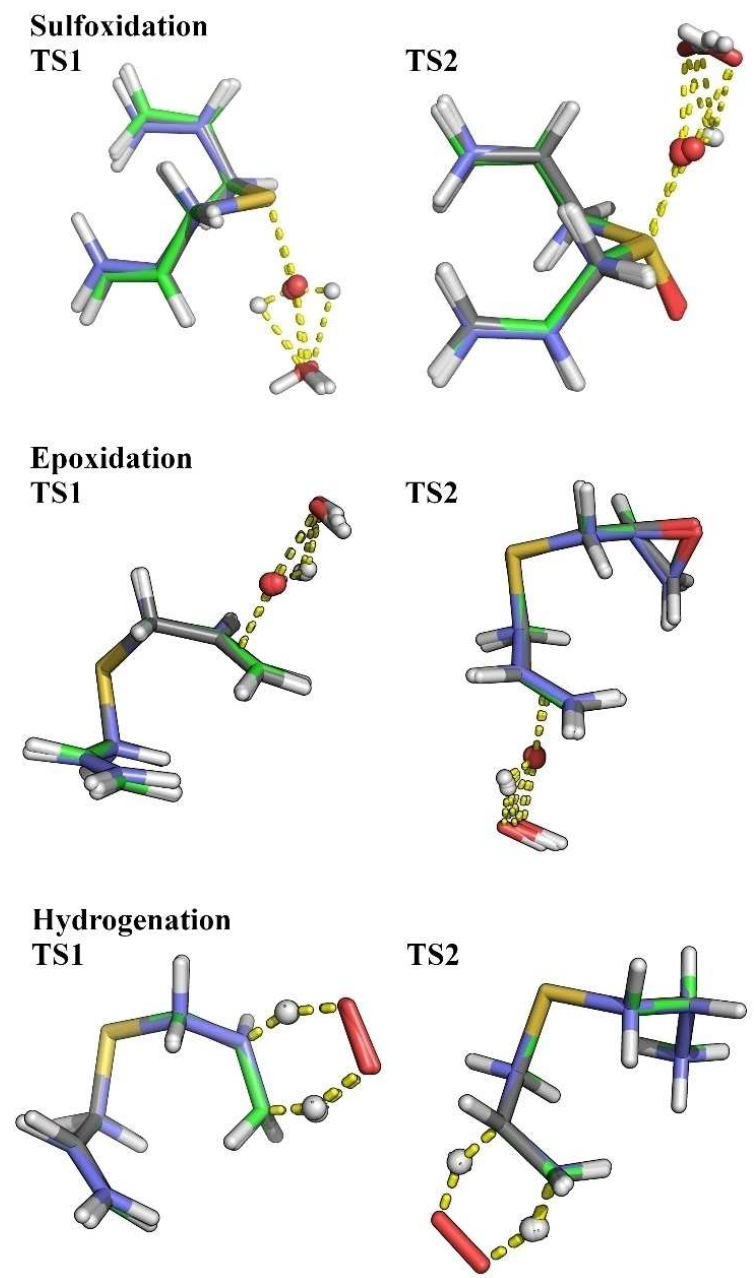

Figure 12. Overlap of the transition states (TS) of the DAS reactions in different environments. Molecules are represented in sticks and carbon atoms are colored according to the phase: gray, gaseous phase; blue, aqueous phase; and green, cyclohexane phase. 
way 2 and pathway 5) and hydrogenation (pathway 3 and pathway 6). Each one of these was studied in gaseous phase and in two condensed environment: polar (water) and nonpolar (cyclohexane) phases.

The quantum calculations predict that the hydrogenation reaction is neither a thermodynamic nor a kinetically favorable process (positives $\Delta G_{R}$ values of about $40 \mathrm{kcal} / \mathrm{mol}$ and very low rate constant values of $10^{-32}$, respectively). The complete sulfoxidation reaction of AMS and DAS resulted to be more spontaneous processes than epoxidation reaction. In addition, the sulfoxidation also showed the highest rate constant values, $10^{-10} \mathrm{~s}^{-1}$, in comparison with $10^{-18} \mathrm{~s}^{-1}$ from epoxidation. We found that all the paths show similar behavior with temperature variation $(293 \mathrm{~K}$ to $313 \mathrm{~K})$. Thus, although the rate constant values indicate that all the reactions occur slowly, it is more probable that the sulfoxidation will be the way of hydrogen peroxide scavenging.

With this study, we provide information on the possible scavenging mechanism of the reactive oxygen species as hydrogen peroxide by two compounds present in garlic with antioxidant properties. In consequence, this information is very useful to the design of new and more potent antioxidants.

\section{Supporting Information Summary}

The supporting information includes the results of the geometrical optimization for AMS and DAS, the molecular structure of reactants, products complexes and TSs for the reactions of AMS and DAS with hydrogen peroxide in non-polar phases.

\section{Acknowledgements}

The authors thank National University of San Luis (UNSL) and CONICET for the financial support.

\section{Conflict of Interest}

The authors declare no conflict of interest.

Keywords: Allyl Methyl Sulfide - Density functional calculations - Diallyl Sulfide - Reaction mechanisms Scavenging of hydrogen peroxide.

[1] X. Wang, R. Liu, Y. Yang, M. Zhang, Food Chem. 2015, 187, 37-43.

[2] F. M. Li, T. Li, W. Li, L. D. Yang, Ind. Crops Prod. 2015, 69, 137-142.

[3] V. Vaidya, K. U. Ingold, D. A. Pratt, Chem. Int. 2009, 48, 157-160.

[4] J. R. Chauvin, D. A. Pratt, Angew. Chem. Int. Ed. 2017, 56, 6255-6259; Angew. Chem. 2017, 129, 6351-6355.

[5] A. Shang, S. Y. Cao, X. Y. Xu, R. Y. Gan, G. Y. Tang, H. Corke, H. V. Mavumengwana, H. B. Li, Foods 2019, 8, 2-31.

[6] K. Sujithra, S. Subramani, I. Dhananjayan, V. Veerasamy, Toxicol. Mech. Methods 2019, 29, 165-176.

[7] S. Dehghani, E. Alipoor, A. Salimzadeh, M. Yaseri, M. Hosseini, C. Feinle Bissete, M. J. Hosseinzadeh-Attar, Phytomedicine 2018, 48, 70-75.

[8] L. D. Lawson, S. M. Hunsaker, Nutrients 2018, 10, 1-49.

[9] J. Casabó, I. Gispert in Estructura atómica y enlace químico, Reverte, Barcelona, 2007

[10] M. Schieber, N. S. Chandel, Curr. Biol. 2014, 24, 453-462.

[11] B. Morgan, K. Van Laer, T. Owusu, D. Ezerina, D. Pastor-Flores, P. Amphonsah, A. Tursch, T. P. Dick, Nat. Chem. Biol. 2016, 12, 437-443.
[12] B. Halliwell, J. M. C. Gutteridge in Free radicals in biology and medicine, fourth ed., Oxford University Press, New York 2007.

[13] M. Ristow, Nat. Med. 2014, 20, 709-711.

[14] I. G. Kirkinezos, C. T. Moraes, Semin. Cell Dev. Biol. 2001, 12, 449-457.

[15] M. G. Díaz, M. F. Andrada, E. G. Vega-Hissi, J. C. Garro Martinez, Struct. Chem. 2019, 30, 237-245.

[16] E. G. Vega-Hissi, M. F. Andrada, M. G. Díaz, J. C. Garro Martinez, Mol. Diversity 2019, 23, 985-995.

[17] M. F. Andrada, J. C. G. Martínez, M. Szori, G. N. Zamarbide, F. T. Vert, B. Viskolcz, M. R. Estrada, I.G. Csizmadia, J. Phys. Org. Chem. 2008, 21, 10481058.

[18] L. A. H. van Bergen, G. Roos, F. De Proft, J. Phys. Chem. A. 2014, 118, 6078-6084.

[19] B. Cardey, M. Enescu, ChemPhysChem 2005, 6, 1175-1180.

[20] J. Chu, J. Yin, B. R. Brooks, D. I. C. Wang, M. Speed Ricci, D. N. Brems, B. L. Trout, J. Pharm. Sci. 2004, 93, 3096-3102.

[21] J. Chu, B. L. Trout, J. Am. Chem. Soc. 2004, 126, 900-908.

[22] N. Taxak, V. Parmar, D. S. Patel, A. Kotasthane, P. V. Bharatam, J. Phys. Chem. A 2011, 115, 891-898.

[23] R. Ishimoto, K. Kamata, N. Mizuno, Eur. J. Inorg. Chem. 2012, 2013, 19431950.

[24] S. Ambati, OA Biotechnol. 2013, 2, 1-5.

[25] P. Tian, Chem. Soc. Rev. 2010, 39, 2071-2082.

[26] H. G. L. Coster, J. Biol. Phys. 2003, 29, 363-399.

[27] A. Panahi, M. Feig, J. Chem. Theory Comput. 2013, 9, 1709-1719.

[28] Gaussian 09, Revision A.02. M. J. Frisch, G. W. Trucks, H. B. Schlegel, G. E. Scuseria, M. A. Robb, J. R. Cheeseman, G. Scalmani, V. Barone, G. A. Petersson, H. Nakatsuji, X. Li, M. Caricato, A. Marenich, J. Bloino, B. G. Janesko, R. Gomperts, B. Mennucci, H. P. Hratchian, J. V. Ortiz, A. F. Izmaylov, J. L. Sonnenberg, D. Williams-Young, F. Ding, F. Lipparini, F. Egidi, J. Goings, B. Peng, A. Petrone, T. Henderson, D. Ranasinghe, V. G. Zakrzewski, J. Gao, N. Rega, G. Zheng, W. Liang, M. Hada, M. Ehara, K. Toyota, R. Fukuda, J. Hasegawa, M. Ishida, T. Nakajima, Y. Honda, O. Kitao, H. Nakai, T. Vreven, K. Throssell, J. A. Montgomery, Jr., J. E. Peralta, F. Ogliaro, M. Bearpark, J. J. Heyd, E. Brothers, K. N. Kudin, V. N. Staroverov, T. Keith, R. Kobayashi, J. Normand, K. Raghavachari, A. Rendell, J. C. Burant, S. S. lyengar, J. Tomasi, M. Cossi, J. M. Millam, M. Klene, C. Adamo, R. Cammi, J. W. Ochterski, R. L. Martin, K. Morokuma, O. Farkas, J. B. Foresman, and D. J. Fox. Gaussian, Inc., Wallingford CT. 2016.

[29] A. D. Becke, J. Chem. Phys. 1993, 98, 5648-5652.

[30] C. Lee, W. Yang, R. G. Parr, Phys. Rev. B. 1988, 37, 785-789.

[31] R. G. Parr, W. J. Yang, Am. Chem. 1984, 106, 4049-4050.

[32] E. R. Davidson, S. Chakravorty, Theor. Chim. Acta. 1992, 83, 319-330.

[33] R. Rousseau, A. Peeters, C. Van Alsenoy, Chem. Phys. Lett. 2000, 324, 189-194.

[34] J. Oláh, C. Van Alsenoy, A. B. Sannigrahi, J. Phys. Chem. A. 2002, 106, 3885-3890.

[35] C. Morell, A. Grand, A. Toro-Labbé, J. Phys. Chem. A. 2005, 109, 205-212.

[36] T. Lu, F. Chen, J. Comput. Chem. 2012, 33, 580-592.

[37] Y. Zhao, D. G. Truhlar, Theor. Chem. Acc. 2008, 120, 215-241.

[38] C. Peng, H. B. Schlegel, Isr. J. Chem. 1993, 33, 449-454.

[39] K. Fukui, Acc. Chem. Res. 1981, 14, 363-368.

[40] A. V. Marenich, C. J. Cramer, D. G. Truhlar, J. Phys. Chem. B. 2009, 113, 6378-6396.

[41] S. Canneaux, F. Bohr, E. Henon, J. Comput. Chem. 2014, 35, 82-93.

[42] B. E. A. Hoyos, R. M. Romano, J. Mol. Struct. 2019, 1182, 54-62.

[43] K. Kamata, T. Hirano, N. Mizuno, Chem. Commun. 2009, 26, 3958-3960.

[44] N. M. R. McNeil, C. McDonnell, M. Hambrook, T. G. Back, Molecules 2015, 20, 10748-10762.

[45] H. Salavati, A. Teimouri, Int. J. Electrochem. Sci. 2017, 12, 7829-7843.

[46] K. Kamata, R. Ishimoto, T. Hirano, S. Kuzuya, K. Uehara, N. Mizuno, Inorg. Chem. 2010, 49, 2471-2478.

[47] E. L. Zins, L. Krim, RSC Adv. 2014, 4, 22172-22180.

[48] S. Thion, A. M. Zaras, M. Szori, P. Dagaut, Phys. Chem. Chem. Phys. 2015, $17,23384-23391$

Submitted: December 10, 2019

Accepted: March 3, 2020 